Trabajos y Comunicaciones, 2da. Época, No 45, e032, marzo 2017. ISSN 2346-8971

Universidad Nacional de La Plata.

Facultad de Humanidades y Ciencias de la Educación.

Departamento de Historia

\title{
Política exterior y movimiento social: análisis de grandes manifestaciones frente a destacados visitantes extranjeros en la Argentina (1963-1983)
}

\author{
Foreign policy and social movement: analysis of big \\ demonstrations against prominent international visitors in \\ Argentine (1963-1983)
}

\section{María Cecilia Míguez * y Leandro Morgenfeld *}
* Universidad de Buenos Aires - Instituto de Estudios Históricos, Económicos, Sociales e Internacionales - CONICET, Argentina | mariaceciliamiguez@yahoo.com.ar ; leandromorgenfeld@hotmail.com

\section{PALABRAS CLAVE}

Política exterior

Movimiento social

Visitas

Relaciones Internacionales

KEYWORDS

Foreign Policy

Social Movement

Visits

International Relations

\section{RESUMEN}

En los estudios sobre la política exterior argentina, en general se presta poca o nula atención al movimiento social que puede surgir alrededor de las medidas y/o posiciones adoptadas por los gobiernos. En este trabajo, incluido en una investigación de más largo aliento sobre la relación de la Argentina con las principales potencias entre 1963 y 1983, interpretaremos las reacciones populares y movilizaciones que se produjeron ante la llegada de visitantes ilustres: De Gaulle (1964), Rockefeller (1969), los presidentes extranjeros que acudieron a la asunción de Cámpora (1973) y la delegación de la CIDH (1979). Cada una de estas visitas generó una conmoción y reacción popular que analizaremos en función de determinar en qué medida condicionaron o reflejaron las políticas exteriores y la inserción internacional argentina en esos años.

\section{ABSTRACT}

In Argentine foreign policy studies, most researchers paid little attention to social movement that arise around the measures and positions taken by governments. In this paper, included in a more extensive investigation about Argentine relations with the big powers between 1963 and 1983, we will interpret the popular reactions and mobilizations that occurred before the arrival of illustrious visitors: De Gaulle (1964), Rockefeller (1969), foreign presidents who attended the Cámpora's inauguration (1973) and the members of the Inter-American Human Rights Commission (1979). Each of these visits provoked a popular reaction and we will determine if they conditioned or reflected foreign policies and international insertion Argentina in those years. 


\section{Introducción}

El presente artículo se inscribe en el campo más amplio de los estudios que vinculan las denominadas variables internas y las relaciones internacionales. Aborda en especial una serie de casos en los que la presión de determinados sectores internos se constituye en una variable explicativa de la política efectivamente implementada. En los estudios sobre la política exterior argentina, en general se presta poca o nula atención al movimiento social que puede surgir alrededor de las medidas y/o posiciones adoptadas por los gobiernos. Al igual que otros actores internos no gubernamentales, los movimientos sociales y populares pueden contarse entre los factores internos que condicionan la política exterior. En este trabajo, en base a una investigación de más largo aliento sobre la relación de la Argentina con las principales potencias entre 1963 y 1983, analizamos las reacciones populares y movilizaciones que se produjeron ante la llegada de visitantes ilustres tales como De Gaulle (1964), Rockefeller (1969), los presidentes extranjeros que acudieron a la asunción de Cámpora (1973) y la delegación de la Comisión Interamericana de Derechos Humanos

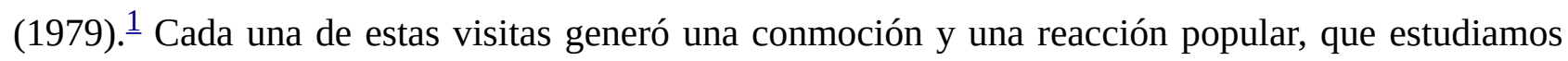
para determinar en qué medida condicionaron tanto la política exterior, como la inserción internacional argentina en esos años.

Si bien son varios los autores que han llamado la atención sobre la importancia de los factores internos en la adopción de determinada política exterior, son pocos los estudios específicos que desarrollan en profundidad dichos condicionantes. Escasean aún más los trabajos que, desde una perspectiva histórica, puedan interpretar el entramado entre dichos condicionantes y el escenario internacional. En general, cuando se abordan las variables internas, éstas quedan reducidas al accionar del poder ejecutivo y de la cancillería -actores centrales sin lugar a dudas- sin que se aborden otras fuerzas sociales y políticas, que también se expresan y tienen su injerencia.

El estudio histórico de la vinculación entre la dinámica y el conflicto interno, por un lado, y las relaciones internacionales y la injerencia de las grandes potencias predominantes en el sistema internacional, por otro, sigue siendo un relativo vacío en las producciones académicas locales. Por lo tanto, para profundizar y discutir los enfoques teóricos, es necesario volver a revisar nuestra historia reciente desde una perspectiva global y multidisciplinaria.

Lo que nos proponemos con este artículo es analizar, a través de algunos hitos significativos del período, la compleja combinación de elementos que influyen en la adopción e implementación de determinadas políticas exteriores y, en consecuencia, del tipo de patrón de inserción internacional, incluyendo una multiplicidad de actores socioeconómicos y políticos.

Al revisar la construcción de los patrones de inserción internacional (concepto más amplio que el de política exterior) cobran relevancia actores no gubernamentales que, en determinados contextos, operan como fuentes de poder predominante incluso respecto de las instituciones políticas. Por ello, la posición de los distintos sectores y, en especial, las movilizaciones sociales y populares tienen según el caso- una importancia destacable como factor explicativo para analizar las conductas adoptadas por los gobiernos frente a las decisiones de política exterior.

¿Por qué estudiar el movimiento social en los casos de las visitas diplomáticas destacadas? Porque cada una de esas visitas puso en evidencia una determinada problemática interna, asociada a la problemática internacional en cuestión. Es en estos casos donde podemos detenernos en el detalle 
del entramado entre una y otra.

\section{La visita de Charles De Gaulle: el escenario de la vuelta del general $\underline{2}$}

De Gaulle realizó en 1964 un extenso viaje por diez países latinoamericanos. En ese momento, gobernaba en la Argentina Arturo Illia, perteneciente a la Unión Cívica Radical del Pueblo (UCRP), en un contexto de proscripción del peronismo. El primer mandatario francés estuvo en el país entre el 3 y el 6 de octubre de ese año.

Desde el punto de vista del estado francés, los vínculos con América Latina se habían transformado en relevantes en un escenario internacional donde una Europa en proceso de unificación buscaba recuperar protagonismo mundial y, al mismo tiempo, terminar con lo que consideraba una relativa subordinación a los Estados Unidos.

En el plano interno, la visita de De Gaulle dio lugar a una serie de posicionamientos y sucesos que daban cuenta del complejo panorama político, que incluía al peronismo, al partido en el gobierno, la oposición de la Unión Cívica Radical Intransigente (UCRI) y, finalmente, a los sectores socioeconómicos predominantes.

Como decíamos, De Gaulle llegó a Buenos Aires el sábado 3 de octubre. Las cuestiones vinculadas con la política exterior francesa frente a los Estados Unidos hicieron que, por ejemplo, el diario La Prensa cubriera con relativa frialdad la presencia del primer mandatario francés. En cambio, $L a$ Nación y Clarín mostraron mucho más entusiasmo.

Quizás uno de los aspectos políticamente más significativos del viaje fue que el peronismo proscripto utilizó esta oportunidad para realizar una demostración de fuerza a partir de la movilización, planear la manifestación del 17 de octubre y contribuir al clima político del denominado Operativo Retorno. A fines de 1963, Perón había declarado que ese sería el último año que pasaría fuera del país, y de allí en más comenzó a impulsarse la consigna de Perón vuelve, como campaña central del peronismo (Page, 1984: 250). En el contexto de la proscripción, de las divisiones sindicales internas al movimiento (algunas de ellas alimentadas por el propio Perón) y del Plan de Lucha de la CGT, cuya fase más intensa se extendió entre mayo y junio de 1964 con la ocupación de múltiples establecimiento fabriles, se gestó la llamada Operación Retorno. A partir de una reunión en Madrid en el mes de agosto con representantes del sindicalismo, trascendió que efectivamente Perón regresaría al país, lo que reavivó en el ámbito local las esperanzas, odios y temores en distintos sectores de la sociedad.

Esa visita debe contextualizarse en un momento en el que se planteaban cada vez más abiertas diferencias entre los líderes del movimiento sindical peronista. Recordemos que el movimiento peronista también estaba sufriendo una serie de divisiones y transformaciones en función de la compleja dinámica política interna y también de los sucesos políticos mundiales. Luego de la normalización de la CGT durante la autodenominada "Revolución Libertadora”, en 1957, el sindicalismo vivió en forma paralela un proceso de radicalización ideológica -expresada en los Programas de La Falda y de Huerta Grande- y, por otro lado, el surgimiento de una línea más dispuesta a la negociación e integración en las estructuras de los gobiernos “semi-democráticos”. El programa de La Falda constituyó uno de los hitos fundamentales de la profundización de la lucha 
obrera durante el período de proscripción. Esa profundización se producía en un contexto particular. La conciencia de la existencia de una parte del mundo explotada por las potencias hegemónicas fue articulándose en una lucha contra la dependencia y el sometimiento económico y político. Por su parte, la Revolución Cubana se iba a convertir en referente para todas las luchas de América Latina, puesto que se trataba de una revolución nacional, antiimperialista y revolución socialista, pero en el continente americano. En esta etapa, y cada vez con mayor énfasis, parte de la lucha sindical trascendió la reivindicación laboral y fue adoptando un objetivo antiimperialista. El Programa de Huerta Grande representó una profundización de los contenidos antioligárquicos y antiimperialistas del peronismo, de acuerdo con el "giro a la izquierda” alentado por el General Perón desde Madrid (Baschetti, 1997). Por otro lado, la línea del sindicalismo vandorista también fue adquiriendo poder y el propio Perón organizó el frustrado Operativo Retorno en diciembre de 1964, también en función de evitar que el proyecto del "peronismo sin Perón” alentado por los “integracionistas” prosperara.

Ante la inminente visita del general De Gaulle hacia fines de septiembre, Perón mandó instrucciones a sus partidarios de que lo acogieran como recibirían a su conductor (Page, 1984; 157). Fue una estrategia inteligente para realizar un acto político de apoyo a Perón, pero con la excusa de vitorear al héroe de la Segunda Guerra Mundial.

Tal como afirma Rogelio García Lupo, en una entrevista realizada por el semanario uruguayo Marcha en 1964, Perón explicó que la política gaullista

“daba oportunidad a los pueblos (...) para que tengan otra alternativa: ni USA ni Rusia ¿Francia? Tampoco Francia propiamente dicha, sino el resto de los pueblos occidentales unidos. Francia no tendrá la fuerza suficiente como para gravitar en contra de los poderosos imperialismos yanqui y ruso. Pero la unión de todos los otros pueblos con el liderazgo de Francia (...) sí la tendrá” (Cit. Garcia Lupo, 1964: 109).

Se conformó, entonces, una comisión de recepción a cargo de los preparativos. Ante la organización de una gran movilización, el día 30 de septiembre por la madrugada, a pocos días de la llegada de de Gaulle, los carteles, volantes, banderas, etc. preparados fueron totalmente confiscados por la policía, por orden del gobierno. La mayoría de esa propaganda incluía la frase "De Gaulle -Perón Tercera Posición” (Castello, 1986: 132).

La posición internacional adoptada por De Gaulle -así como su estilo de liderazgo- aparecía como bandera susceptible de ser capitalizada políticamente por un movimiento que se encontraba excluido del sistema político, pero que constituía el eje de las problemáticas del gobierno y de los sectores económicos predominantes. Los actos de bienvenida a De Gaulle podrían configurar un escenario excelente que preanunciara la vuelta de Perón, tan temida por muchos.

El accionar de la policía no impidió que los afiliados convergieran en el Aeroparque de la ciudad de Buenos Aires el sábado en la mañana, a recibir al mandatario francés, por decisión de la Junta Metropolitana del Justicialismo. Se trataba de grupos pequeños, mientras que el resto se agrupó en los locales seccionales para dirigirse hacia plaza Once. Otra parte se concentró en Plaza Francia, donde se realizaría el acto de entrega de las llaves de la ciudad de Buenos Aires por parte del intendente. Más tarde, las columnas se encaminaron hacia Plaza de Mayo y de allí a la Plaza 
Congreso, ya que el siguiente acto del general era un discurso en la Asamblea Legislativa. Allí los manifestantes chocaron con la policía, hubo gases y disparos de armas de fuego. ${ }^{3}$ Durante los actos, se escucharon constantes cánticos “Perón- De Gaulle- Tercera Posición”.

Dentro del recinto, De Gaulle reafirmó la posición que había tenido durante su viaje, expresando: "Vosotros y nosotros tenemos nuestros orígenes en la latinidad y en la cristiandad". 4

En el discurso ofrecido por el presidente Illia, éste hizo referencia explícita a los conflictos del comercio internacional, señalando que “dos tercios del mundo aguardan las respuesta a los principios que la América Latina enunció solidariamente en Alta Gracia y que en Ginebra encontraron la coincidencia de setenta y siete países. Por lo que tradicionalmente ha sido Francia, por lo que es Francia, nosotros esperamos que seguirá acrecentándose el apoyo francés a esa gran causa”. $\underline{5}$ La reunión con el presidente argentino se produjo al día siguiente en la Residencia de Olivos. Allí el primer mandatario francés planteó que la paz mundial no podía depender exclusivamente del acuerdo entre Washington y Moscú, sino que debía asentarse sobre la participación activa del resto del mundo. A esos fines Francia impulsaba la Unión Europea occidental, "es decir, Francia con Alemania e Italia principalmente, y también con Bélgica y Holanda”, y estaba dispuesta a apoyar el desarrollo de América Latina porque también era un actor necesario en función del equilibrio mundial. $\underline{6}$

La visita debe inscribirse en toda una estrategia de Francia para plantear una posición de relativa distancia y autonomía respecto de los Estados Unidos. Respecto de la relación con la potencia americana, señaló:

"Naturalmente nosotros comprendemos las razones que explican las particulares relaciones existentes entre América Latina y Estados Unidos de América del Norte. Forman parte del mismo continente y las distancias no son tan grandes. Por otra parte, los Estados Unidos tienen medios poderosos, sobre todo de naturaleza económica. Es natural que ustedes tengan fuertes vínculos cercanos con ellos. Lo que nosotros deseamos, es que esos vínculos no sean tales que les impidan transformarse en una entidad internacional propia que no se confunda con los Estados Unidos (...) El devenir del mundo depende de una paz que será condicionada por la organización de Europa y por la aparición de una América Latina definida de un modo específico"ㅍ․

El diario ABC de Madrid hizo explícita referencia a que "más que esperar créditos -que sabe improbable-, la Argentina buscaba fomentar sus exportaciones de carne, a través de alguna facilidad aduanera del Mercado Común, y especialmente una moratoria para los 150 millones de deuda que el país tiene con el Club de París del que Francia es miembro”. $\underline{8}$

En lo inmediato, la visita a Argentina dejó únicamente por saldo convenios de cooperación cultural, técnica y científica, suscriptos por los cancilleres de ambas naciones, que incluyeron la posibilidad de que investigadores argentinos se formaran para la construcción de la central atómica de Atucha.

La estancia del mandatario francés continuó con una recorrida por establecimientos fabriles en la ciudad de Córdoba. Las manifestaciones en esa provincia concluyeron en grandes disturbios entre el peronismo y la policía, con un saldo de 29 heridos. Esa misma tarde, 40 diputados de la UCRP 
apoyaban un proyecto que promovía la reincorporación de militares colorados. El embajador de Francia en Argentina, Jacquin de Margerie, relató así al canciller M. Couve de Murville, los sucesos de la provincia de Córdoba:

“Decenas de personas se presentaron en las veredas a lo largo de veinticinco kilómetros, a travesando la ciudad. Aclamaron al General de Gaulle con un entusiasmo delirante. Dentro de la fábrica de automóviles IKA, los obreros lo saludaron con un fervor conmovedor. La recepción vibrante y popular de Córdoba superó por mucho la recepción de Buenos Aires. Por mala suerte, fue allí donde se produjeron graves incidentes. Era conocido que los peronistas querían manifestarse y que habían organizado una suerte de marcha sobre la ciudad. A pesar de las advertencias del poder central, la policía provincial, celosa de sus prerrogativas, se dejó desbordar. Mientras que el General visitaba la fábrica, los manifestantes intentaron ocupar el Palacio de Justicia. Fueron reprimidos con carros de incendio y gases lacrimógenos. También hubo tiros con armas de fuego. Algunos -los primeros, según afirma la policía- por los peronistas, pero la mayoría por los policías que manifestaron haber perdido su sangre fría. Hubo una veintena de heridos, entre ellos algunos graves (...)”.

La revista Primera Plana rápidamente afirmó que los incidentes habían provocado la proliferación de rumores golpistas "entre militares decididos a ajustar cuentas al peronismo, si el gobierno no se animaba a hacerlo", porque se estaban cerrando "los caminos de la comprensión", ya que los disturbios "habían conseguido arrancar al país del justo medio y arrojarlo sobre extremos de violencia”. $\underline{10}$ La interpretación que realizaba la revista era que el peronismo había utilizado a Charles De Gaulle “como pretexto para un recuento globular de sus fuerzas y para una demostración antigubernista, operaciones cuidadosamente preparadas, vocingleras y compactas, pero exiguas frente a los cálculos que los dirigentes se habían trazado y al temor que despertaron en muchos sectores”. $\underline{11}$

Las debilidades iniciales del gobierno de Illia se profundizaban y las amenazas latentes de golpe de estado crecían entre heterogéneos sectores. El presidente intentó restar importancia a la cuestión. En la Cámara de Diputados se daba a conocer al día siguiente un proyecto de Estatuto de los Partidos Políticos que preveía la concurrencia del Partido Justicialista a los comicios de marzo de 1965. El gobierno aparecía, desde el punto de vista de los sectores antiperonistas, como extremadamente débil frente al peronismo y su avance, por su política conciliadora y por su objetivo de incorporar al movimiento a la política. Entre los peronistas, a pesar de las señales de estatismo, intervención y aumento del gasto público, Illia seguía siendo visto como un aliado de aquella Revolución Libertadora que había derrocado al líder y, por lo tanto, era el blanco de sus ataques.

Los sucesos de Córdoba fueron utilizados por los primeros -en especial la fracción colorada de los militares, y sus aliados civiles en el parlamento-, para lograr que el levantamiento de la proscripción se demorara. La oposición al Operativo Retorno unificaría a azules y colorados, a desarrollistas e intransigentes, a conservadores y radicales. El mismo telegrama del embajador francés sacaba una correcta conclusión:

"Los lamentables sucesos que se produjeron serán probablemente explotados. Nadie hará responsable al General de Gaulle -cuyo viaje fue un éxito- pero sí al gobierno, 
cuya actitud de tolerancia frente a la campaña peronista se ha revelado perjudicial. El presidente Illia ha hecho declaraciones que tienden a minimizar los incidentes y la importancia de los grupos de agitadores -relativamente débil en efecto- directamente responsables. Es evidente que será objeto de severas críticas. Desde la derecha, de parte de aquéllos que juzgarán que no estuvo a la altura de sus responsabilidades, y desde el costado peronista, porque corrió sangre del pueblo”. $\underline{12}$

\section{“Malvenido Míster Rockefeller”}

Cuando asumió, en enero de 1969, el presidente estadounidense Richard Nixon procuró reforzar los lazos con América Latina y el Caribe. Consultó al Secretario General de la OEA, Galo Plaza, quien le sugirió que enviara al gobernador de New York, Nelson A. Rockefeller, a visitar los países de la región. Si bien éste se mostró sorprendido por la invitación de su ex rival en la interna del Partido Republicano, aceptó rápidamente la propuesta. Una vez más, se transformaría en un actor fundamental de las relaciones con los países latinoamericanos. $\underline{13}$ Con su clásica grandilocuencia, Rockefeller transformó rápidamente la iniciativa para convertirla en una Misión Presidencial, que abarcaría 20 países latinoamericanos. Si bien el gobernador tenía un gran ascendente entre las clases dominantes de la región, para las izquierdas y los movimientos nacionalistas su apellido era sinónimo de dominación imperial. Así, las visitas a cada país fueron acompañadas por episodios de protesta y violencia. Al inicio de la gira, por ejemplo, un manifestante fue asesinado en Honduras. Gerald Colby y Charlotte Dennett caracterizaron a la misma como el "Rocky Horror Road Show", por la oleada de protestas y sentimientos anti-yanquis que generó (Colby y Dennett, 1995). Como puede apreciarse en el informe oficial tras la gira, el viaje permitió al gobierno estadounidense profundizar el conocimiento sobre América Latina (Rockefeller, 1969). Además, Rockefeller construyó numerosos vínculos que ampliaron la participación estadounidense en muchas obras públicas e incluso de caridad.

Rockefeller llegó a Buenos Aires el domingo 29 de junio, en la última etapa de los cuatro viajes en que se dividió su extensa gira por América Latina. Arribó en el momento quizás menos propicio: justo frente en el tercer aniversario del golpe de Onganía -lo cual motivó sendas movilizaciones de protesta-, exactamente un mes después del estallido del Cordobazo y horas antes de que asesinaran a Vandor, importante dirigente de la CGT oficialista. Pero también coincidió con el día en que la Administración Nixon anunciaba la eliminación de la "cláusula de adicionalidad”, incluida en los programas de asistencia económica estadounidense desde el año 1964. Esto respondía a un viejo reclamo latinoamericano y es casi el único gesto de la nueva administración republicana, frente a los renovados reclamos de la región, plasmados en la reunión de Viña del Mar. $\underline{14}$

Rockefeller se entrevistó con Onganía, y luego, junto a 29 asesores, se reunió con distintos estamentos del gobierno argentino y 280 representantes de la agricultura, empresa, cultura, economía, educación, finanzas, salud, medios de comunicación, militares, científicos, urbanistas y delegados de organizaciones de mujeres y de la AID. El canciller argentino ofreció una cena a Rockefeller y sus asesores. El enviado estadounidense ofició de anfitrión en una velada destinada para intelectuales, periodistas y representantes de la cultura y organizó una recepción a la que asistieron 400 funcionarios de distintos sectores y representantes del empresariado local. El jueves 1 de julio, tras dos días en Buenos Aires, la misión abandonó el país. 
La visita del gobernador de New York a Buenos Aires fue precedida por una ola de protestas: contra él y contra el gobierno argentino, que llevaba tres años de dictadura y represión:

"La llegada de Rockefeller -a la que precedió el arribo de más de dos millares de norteamericanos expertos en organización, seguridad, relaciones públicas, etc.- se producirá entre medidas extremas de seguridad. El gobierno, que espera manifestaciones estudiantiles para el domingo y lunes, ha arrestado más de mil personas, la mayoría de ellas calificadas por las autoridades como agitadores comunistas. Por su parte, la CGT anuncia un paro nacional para el martes 1 de julio, último día de estancia de Rockefeller en el país. (...) Respecto a las manifestaciones antinorteamericanas -que hasta ahora han causado un muerto, muchos heridos y más de mil personas arrestadas, tanto en Buenos Aires como en Córdoba y Rosario- el gobierno ha tomado también providencias”. $\underline{15}$

Todas las crónicas de la época reconstruyen las amplias movilizaciones de protesta contra Onganía y Rockefeller: Buenos Aires, Córdoba, La Plata y Rosario fueron el epicentro de las protestas. Además de las múltiples marchas, hubo acciones contra empresas estadounidenses, como Rosario Refrescos Coca Cola (estalló un artefacto explosivo en la fábrica), Xerox, el Bank of America o la cadena de supermercados Minimax, propiedad del grupo Rockefeller, cuyos locales fueron incendiados, tras lo cual la empresa decidió retirarse del país. El 30 de junio, la Federación de Empleados de Comercio, por ejemplo, publicó una Solicitada, titulada elocuentemente: "Mr. Rockefeller: a qué viene?”. En la misma se narran las pésimas condiciones de trabajo imperantes en los supermercados Minimax y la preocupación, a partir de las 14 sucursales de los mismos que fueron destruidas con bombas durante su visita, poniendo en riesgo los puestos de trabajo: "USTED es el verdadero responsable de la destrucción de sus Minimax", cierra provocativamente la solicitada. $\underline{16}$ También hubo expresiones artísticas en contra de la visita del gobernador de New York, entre las que se destacó “Malvenido Míster Rockefeller”. $\underline{17}$ Los estudiantes nucleados en la Federación Universitaria Argentina y el Movimiento de Sacerdotes del Tercer Mundo, por su parte, repudiaron enérgicamente la visita del enviado de Nixon. $\underline{18}$

La respuesta de Onganía fue la represión y más represión. Se dispusieron 40.000 efectivos de las distintas fuerzas de seguridad para proteger a Rockefeller. La mayor movilización de protesta, apoyada por el peronismo, el radicalismo y los partidos de izquierda, se realizó en plaza Once el viernes 27 de junio. Allí fue asesinado el periodista Emilio Jáuregui, víctima fatal del accionar policial. Éste había sido ex secretario general de los trabajadores de prensa, sindicato que había sido intervenido tras el golpe de 1966.

La violencia, aunque por otros motivos, tendría un nuevo hito pocas horas después de la llegada de Rockefeller: el asesinato de Vandor. El sindicalista estaba en ese momento tratando de evitar el paro nacional convocado por la CGT de Ongaro en contra de Rockefeller y de Onganía. En la mañana del lunes 30 de junio, hasta el atentado contra Vandor, la atención general giraba en torno a la visita de Rockefeller. Con fuertísima custodia policial, el gobernador de New York se trasladó desde el Palacio San Martín a la Casa Rosada. Lo acompañaba una gran comitiva y diversos funcionarios argentinos: Elvio Baldinelli, Secretario de Comercio Exterior, Lorenzo Raggio, Secretario de Agricultura y Ganadería, Eduardo Roca, embajador argentino en Washington, y Mariano Grondona, 
asesor general de Planeamiento y muy vinculado con el sector de los azules de las fuerzas armadas.

En una carta confidencial de Leonard J. Saccio -a cargo de la Embajada de Estados Unidos en Argentina- a Rockefeller, el diplomático estadounidense comenta las visitas previas de Nixon a Buenos Aires (1958 y 1967 -en esta última, se entrevistó con Onganía, y Saccio estuvo presente-) y le brinda información para el inminente viaje. Saccio comenta la reluctancia argentina a ser considerados como latinoamericanos, que el país no espera ningún énfasis especial en la asistencia de tipo convencional, sino más bien que sus preocupaciones se centraban en el comercio y en la apertura de mercados en los países desarrollados, principalmente dificultada por las tarifas y las medidas para-arancelarias. También destaca las quejas del gobierno argentino por la posición estadounidense en las agencias internacionales, en contra de otorgar asistencia financiera al país, por la supuesta buena situación financiera local. $\underline{19}$ La delegación estadounidense contaba con materiales que analizaban el creciente sentimiento anti-yanqui (un extenso informe de Civita, el dueño de Editorial Abril, daba cuenta de esa tendencia), pero también las luchas sociales de resistencia al régimen militar encabezado por Onganía. Por ejemplo, entre los informes con que contaba Rockefeller se encontraba “Argentina's mosaic of discord 1966-1968”, de Kenneth F. Johnson, en el que, a lo largo de 60 páginas, se describían los distintos sectores peronistas y de izquierda que luchaban contra la dictadura militar. $\underline{20}$

Conscientes del rechazo que generaba su presencia, los asesores de Rockefeller habían preparado un discurso inicial que hablaba de los esfuerzos que debía hacer Estados Unidos para fomentar la unidad hemisférica. $\underline{21}$ Anticipaba luego lo que plantearía en su Informe a Nixon: Estados Unidos debía revertir su política hacia América Latina, para lo cual era necesario realizar concesiones económicas.

El 30 de junio, a las 4 de la tarde, Rockefeller ofreció un diálogo off the record a periodistas en el Hotel Plaza. Su primera referencia fue al asesinato de Vandor, ocurrido apenas unas horas antes, y expresó su pena y planteó que le habían informado que el líder sindical era un indiscutido anticomunista. Luego, señaló que el asesinato del máximo dirigente de la CGT colaboracionista no modificaría sus planes en Buenos Aires. $\stackrel{22}{ }$ Más allá del incidente, se refirió a la reunión de la noche anterior con distintos representantes sectoriales, y al desayuno de ese mismo día con empresarios industriales, comerciantes y productores agropecuarios (UIA, CGE, SRA, Bolsa de Comercio, Cámaras de Exportadores e Importadores, etc), que le expresaron la preocupación por el subsidio estadounidense a los productores de trigo, lo cual afectaba las ventas argentinas a mercados como el brasilero, y por las dificultades para ingresar la carne argentina en el mercado estadounidense. $\underline{\underline{23}}$ También se refirió Rockefeller a las quejas gubernamentales por la balanza comercial negativa con Estados Unidos, por 2.000 millones de dólares en los últimos 15 años. En relación con su entrevista con Onganía ese mismo mediodía, que se extendió por dos horas, el representante estadounidense señaló que el presidente argentino no planteó, a diferencia de los mandatarios de otros países, reclamos vinculados a la "ayuda económica”, sino a temas relacionados al comercio, inversiones, tecnología, entrenamiento científico, intercambio estudiantil y cultural. También, anticipando lo que luego serían las conclusiones de su informe oficial tras la gira y reforzando sus primeras declaraciones públicas ni bien arribó a Buenos Aires, planteó que era necesario un cambio total en 
las políticas de su país hacia América Latina.

Más allá de las múltiples protestas, no faltaron, claro está, las expresiones de buena voluntad hacia Rockefeller, y mucho menos los pedidos de financiamiento a sus fundaciones. En el RAC hemos registrado decenas de cartas solicitándole, a título personal, asistencia financiera para los más diversos fines. Victoria Ocampo, por ejemplo, es una de las que frecuentemente le escribía. En ocasión de la visita que estamos analizando, Ocampo le envió una pequeña nota, de puño y letra, lamentándose por estar recién operada y convaleciente y no poder asistir a la recepción a la cual la Embajada estadounidense la había invitado: “No se imagina usted cuanto lo siento. Ante todo, por no poder saludarlo a usted como persona, como representante de lo que usted es (aparte ya del país extraordinario que usted representa). Hubiera sido para esta amiga un placer". $\underline{24}$ Ya de vuelta en New York, el propio Rockefeller le contestó a Ocampo, el 25 de julio, deseándole una pronta recuperación.

Estados Unidos intentó que la visita a la Argentina sirviera para limar las asperezas bilaterales y recomponer un vínculo que había sido promisorio tras el golpe de 1966, cuando los jefes militares locales se mostraron dispuestos a defender la Doctrina de Seguridad Nacional. A los ojos de la Casa Blanca, y en el contexto del recrudecimiento de la guerra fría en América Latina, no era poco contar con un firme aliado en la lucha anti-comunista en el Cono Sur. Más viniendo de un país que históricamente había enfrentado las políticas interamericanas de Washington. Pero el entendimiento intergubernamental -aún con los límites y matices - no se derramaba hacia el resto de la población. La masividad de las movilizaciones en contra de la visita de Rockefeller, símbolo del imperialismo estadounidense en la región, era una de las manifestaciones del ciclo de auge de las luchas populares que había empezado pocos días antes con el Cordobazo y se extendería por varios años. Apenas semanas después de la gran movilización política y social con epicentro en Córdoba, en pleno aniversario del golpe de Onganía y justo en el momento del asesinato de Vandor, la fecha de la visita de Rockefeller a Buenos Aires no pudo ser menos oportuna.

\section{La asunción de Cámpora y la inserción internacional argentina $\underline{25}$}

El acto de toma de posesión del cargo presidencial de Héctor Cámpora constituyó un símbolo del cambio del alineamiento político de la Argentina en el mundo. Prueba de la relevancia mundial del hecho fue la asistencia de 86 delegaciones internacionales a la asunción presidencial. $\underline{26}$ Tres delegaciones incluían a los primeros mandatarios: la de Uruguay, con la presencia de Juan María Bordaberry, y los dos protagonistas de la jornada: el presidente chileno Salvador Allende y su par cubano, Osvaldo Dorticós. Ese protagonismo y la lectura que en la política interna se haría de estas dos últimas presencias, son elementos que ejemplifican el nuevo escenario. Quizás las ausencias, menos conocidas, también sean elocuentes respecto del panorama político interno. El dictador Hugo Banzer no asistió por la compleja situación interna de su país, enviando a su canciller, y el Secretario de Estado de Estados Unidos, William P. Rogers, quien se encontraba cerrando una amplia gira por América Latina, no pudo presenciar el acto de asunción porque una multitud que coreaba consignas antiimperialistas le impidió llegar hasta la casa de gobierno (Svampa, 2003: 347). Algo similar le sucedió a Bordaberry, quien fue objeto de abucheadas por parte de las 
multitudes en la plaza, lo que llevó al propio Cámpora a disculparse luego. $\underline{27}$

Los días previos a la asunción, la prensa fue registrando la llegada de todas las delegaciones extranjeras. Nutridas manifestaciones de jóvenes y estudiantes se hicieron presentes en las embajadas de Perú y Chile, y se presentaron en los lugares donde estaban alojados Dorticós y los delegados de Vietnam del Norte, ofreciendo gestos de solidaridad. $\underline{28}$

Conocidas son las variadas manifestaciones de festejo que se adueñaron de la escena política del 25 de mayo de 1973, por parte, principalmente, de la juventud peronista (Bonasso, 2006). La policía se retiró. Un grafitti escrito en la pared de la mismísima Casa Rosada que decía "Casa Montonera” daba cuenta de las expectativas que abrazaba el nuevo gobierno. Cámpora y Vicente Solano Lima, su compañero de fórmula, no pudieron desfilar en el coche presidencial desde el Congreso hacia Casa de Gobierno porque la marea humana lo impidió. Llegaron en helicóptero. Los cánticos y el famoso "Devotazo", la liberación de los presos políticos que residían en la cárcel de Devoto luego de la firma del decreto presidencial de amnistía, constituyen algunos de los hitos de esa asunción.

Sin embargo, nos interesa aquí analizar las manifestaciones que se organizaron en relación con las visitas internacionales, y cómo se vincularon con el clima político interno. Allende se presentó en la Casa Rosada alrededor del mediodía y fue recibido por cánticos que decían "Allende y Perón, un solo corazón”.

En su discurso desde los balcones de la Casa de Gobierno, Cámpora dijo:

“...la Argentina propugnará una relación estrecha con los países del Tercer Mundo, y particularmente con los de América Latina (...) los países pequeños, si persisten en su aislamiento, tendrán cada vez mayores dificultades en resistir la presión que aquel [el mundo desarrollado] ejercerá en búsqueda de alimentos, materia prima, y lugares para la radicación de sus industrias sucias, para que sigan produciendo a bajo costo, preservando su propio ambiente, pero a riesgo de contaminar el de las regiones periféricas. (...) Mi Gobierno propugnará también una relación más estrecha con todos los países de América Latina que aliente esta misma vocación por su liberación”. $\underline{29}$

El presidente electo hizo especial hincapié en la defensa del antiimperialismo y del principio de no intervención y en la crítica a la OEA, así como en la necesidad de que la Argentina tuviera relaciones con todos los países, incluido Cuba. En oportunidad del homenaje realizado por la Asamblea Legislativa a las delegaciones extranjeras del día 26 de mayo, el nuevo mandatario afirmó:

"Reafirmamos como valores universales los que ustedes levantan como banderas que serán invictas: paz entre los pueblos, diálogo para superar las dificultades, amistad por sobre las fronteras materiales, y derrumbar las fronteras ideológicas, justicia social y no miseria" (...) "Por eso yo puedo decir que en esta hora ser latinoamericano no es sólo un sentimiento ni es haber nacido en la misma tierra; es una responsabilidad para todos nosotros, porque nuestros pueblos no pueden seguir sometidos y no pueden la miseria, el dolor y el sufrimiento, marcar la angustia de millones de latinoamericanos” $\underline{30}$. 
La tendencia hacia el abandono de la idea de las “fronteras ideológicas” en el campo de las relaciones económicas internacionales no era nueva. Eduardo Mc Loughlin, canciller del dictador Alejandro Agustín Lanusse, fue el encargado, por ejemplo, de normalizar las relaciones diplomáticas, consulares y económicas entre los gobiernos de la Argentina y Cuba, en el marco de toda una estrategia de acercamiento a los países “del este”. Desde comienzos de la década de 1970, y especialmente a partir de la presidencia de facto de Lanusse, comienza un viraje en la orientación de las relaciones económicas internacionales conocido como la "apertura hacia el Este”. Por diversos factores, una poderosa fracción de la clase dominante argentina comenzó a promover desde 1970 la negociación de un tratado comercial con la Unión Soviética. Entre esos factores se encontraban los intereses de negocios vinculados a dicha superpotencia que habían venido creciendo desde el período desarrollista, y las dificultades para colocar los productos en la Europa Comunitaria. Este viraje culminará en una nueva relación triangular hacia mediados de la década de 1970, consolidado por la dictadura militar implantada en 1976, ocupando la Unión Soviética durante unos años el vértice anteriormente ocupado por Europa occidental y antaño por Inglaterra. $\underline{31}$ Pero la asunción de Cámpora, a diferencia del período dictatorial, permitió que el gobierno cubano demostrara su afinidad con el nuevo presidente, y con la etapa que parecía abrirse. A las cuestiones económicas de la inserción internacional argentina, que continuarían su marcha, se sumaba ahora una afinidad política que iría en un carril paralelo, y que, a diferencia de las primeras, no se extendería en el tiempo.

El clima político del período y la vinculación entre política interna y relaciones internacionales se confirmó con la significativa participación de Dorticós en la conmemoración del cuarto aniversario del Cordobazo, el 29 de mayo. Allí, uno de los cánticos escuchado fue "Cuba y Perón, un solo corazón”. Del “De Gaulle, Perón, un solo corazón” de 1964, que analizamos en la primera parte del trabajo, a esta nueva versión, había una importante diferencia. Era el reflejo de la izquierdización de un sector del peronismo, y también de la reorientación de las relaciones internacionales argentinas.

Tal como se preanunciaba, los lazos diplomáticos con la isla se reanudaron el 28 de mayo a través de una declaración conjunta entre los cancilleres Juan Carlos Puig y Raúl Roa García, de Argentina y Cuba respectivamente. Se cerraba la etapa iniciada con la ruptura de relaciones de febrero 1962. La prensa del 29 de mayo publicaba, además, la explícita intención de gobierno de reanudar las relaciones con Alemania Oriental y Corea del Norte. $\underline{32}$

No era un detalle menor el hecho de que los únicos otros dos países que habían restablecido relaciones con la isla caribeña eran el Chile de Allende y el Perú de Velazco Alvarado. Pero lo más interesante fue la materialización de ese vínculo.

El 4 de agosto de 1973, el ministro de economía, José Ber Gelbard, ya durante la presidencia provisional de Raúl Lastiri, anunció que la Argentina otorgaría a Cuba un préstamo de seis años por un monto anual de 200 millones de dólares, para la adquisición en nuestro país de maquinaria liviana, especialmente del sector automotriz y agrícola. $\frac{33}{}$ El primer antecedente comercial había sido la venta de 50.000 toneladas de maíz en el mes de julio. En efecto, el crédito otorgado por la Argentina fue el mayor destinado a un país de América Latina (Ramírez, 1973: 12).

Tal como afirmaba el subsecretario de Relaciones Económicas de la Cancillería, Leopoldo 
Tettamanti, esta medida, al igual que la propuesta de integrar el Pacto Andino, constituían parte de una "estrategia multipolar que permita sustraer a la Argentina del predominio sectorial de cualquier de los sectores en pugna”, y que si bien el Mercado Común Europeo continuaría siendo prioridad por razones históricas, "el acrecentamiento del comercio con los países de economías centralizadas de Europa, Asia y África, no debe ser de ningún modo descuidado”. $\underline{34}$ La confirmación de este crédito a la isla daba cuenta de la intención argentina de ocupar un rol de proveedor industrial en un nuevo bloque latinoamericano (Horovitz, 1973: 11).

En cuanto a la posición más puramente política, más allá de la renuncia de Cámpora y el interregno de Lastiri, durante la tercera presidencia de Juan Domingo Perón, el líder mostraría especial interés en la reincorporación de Cuba al sistema interamericano. Lo haría en sus intervenciones en la Sexta Sesión Extraordinaria de la Asamblea General de la ONU, realizada en Nueva York, y también en abril de 1974, en la Tercera Asamblea General de la OEA, en Washington.

Tal como afirmaba en ese mismo momento Juan Carlos Portantiero, el restablecimiento de las relaciones con Cuba era "un hecho político de primera magnitud, la punta por la cual puede desmadejarse un ovillo significativo que va más allá de un hecho protocolar” (Portantiero, 1973: 8). Una nota del Diario La Opinión del día posterior a la asunción de Cámpora afirmaba con contundencia:

“Cuando ayer a las 14 Salvador Allende y Osvaldo Dorticós fueron invitados a poner su firma al pie del acta de traspaso del poder presidencial, la política exterior argentina había hallado el símbolo para su cambio de rumbo. Ese cambio está en la afirmación del interés nacional por encima de toda otra consideración, en la solidaridad activa con los pueblos del Tercer Mundo que luchan por liberarse, en la amistad de todas las naciones con respecto a su autodeterminación, en el rechazo del colonialismo, en la denuncia de la OEA y en el ejercicio de una diplomacia abierta y pública” (Alonso, 1973: 7).

Volviendo a las manifestaciones populares, quizás la más significativa fue en la ciudad de Córdoba, donde Dorticós asistió el 29 de mayo al aniversario del Cordobazo. Allí visitó la planta de Fiat Concord y luego tomó contacto real con organizaciones sindicales y estudiantiles. Miles de personas participaron de la asamblea que conmemoró los sucesos de 1969. Allí, el estribillo más repetido fue “Cuba, del brazo, de nuestro Cordobazo”. $\underline{35}$

Durante los discursos, el vicegobernador de la provincia, Atilio López, afirmó que la Argentina había "tomado el camino de nuestra liberación, a sólo cuatro días de asumir el gobierno popular” $\underline{6}$. Hablaron en el acto René Bustos (de Montoneros), Raúl Mena (del ERP) y un representante de las Fuerzas Armadas Peronistas, y todos coincidieron en la necesidad de "profundizar la revolución en el camino hacia el socialismo". $\underline{37}$

Mario Bizzi, diputado por el FREJULI, afirmó que "los funcionarios electos saben perfectamente que si no cumplen con su programa de liberación el pueblo los sacará a patadas”.

Ciertos incidentes no se hicieron esperar. Durante el acto, pudo percibirse la distancia entre sectores de izquierda más radical, como el caso de Agustín Tosco y René Salamanca, y los de un peronismo ortodoxo, nucleado en parte en las 62 Organizaciones. Las interrupciones a las alocuciones de los 
dirigentes citados, así como la del sindicalista Carlos Dreysin, de las 62, pusieron en evidencia la heterogeneidad que la visita de Dorticós había convocado.

Durante aproximadamente tres horas se oyeron una serie de proclamas emitidas desde la estación radial La Voz de la Libertad, que fue tomada pacíficamente y sin resistencia alguna, y que alentaban el camino de la revolución socialista y la defensa del nuevo gobierno popular, así como del gobernador Ricardo Obregón Cano y su vice (Atilio López). $\underline{38}$

La siguiente jornada fue en Mendoza. Dorticós fue recibido por una multitud en el aeropuerto de Plumerillo. Al igual que en el caso de Córdoba, la muchedumbre se abalanzaba sobre él, con algarabía, buscando acercarse. Los cánticos avivaban a Perón, al Che Guevara, a Fidel Castro, Evita y la patria socialista. $\underline{39}$

Por su parte, el periódico La Prensa describía críticamente el privilegio otorgado a los primeros mandatarios de Chile y Cuba.

“Los señores Allende y Dorticós fueron convertidos en las figuras centrales de las celebraciones recientes, desde las ceremonias protocolares hasta su concurrencia a un partido de fútbol en compañía del presidente Cámpora. En la oratoria de estos agitados días, lo mismo que en las organizadas escenas de aplauso callejero, se destacó asimismo esa preferencia, mezclada también con nuevas invocaciones a la 'unidad continental'. Por su parte, esos mismos elegidos, se refirieron con insistencia al mérito que para tal unidad tenían los actos a que asistían, pero no dejando de mencionar en ningún caso la esencial afinidad de sus gobiernos con el nuevo régimen de nuestro país”. $\underline{40}$

La presencia y ovación a estos dos visitantes ponía sobre la mesa la discusión sobre qué tipo de "unidad continental” buscaba implementar el gobierno. La orientación latinoamericanista de Cámpora reflejaba claramente un giro a la izquierda que muchos sectores no estaban dispuestos a tolerar, incluso dentro del propio partido y movimiento peronista. Visitantes extranjeros, política exterior y conflicto político interno se entrecruzaban.

En efecto, las características de la asunción de Cámpora fueron una señal que sería rápidamente interpretada a nivel mundial. Ello puede apreciarse en la repercusión en la prensa española, estadounidense, francesa y, por supuesto, regional, reproducida en el diario La Opinión. En especial, el periódico The Guardian, a través de la pluma de su periodista Richard Gott, publicó que "lo que da importancia a la vuelta del peronismo, es que, pese a su pasado político, el movimiento tiene ahora un neto cariz de doctrina de izquierda antiimperialista”. $\underline{41}$

La nueva y marcada posición política del gobierno era el reflejo de las tendencias internas del peronismo que habían alcanzado el poder. Las definiciones incorporadas al Plan Trienal presentado para el período 1973-1977 incluían claramente una estrategia multipolar, enmarcada en una cierta clausura del ciclo de guerra fría.

Más allá de las diferencias que se irían evidenciando, fue un propósito central del gobierno peronista que asumiría como continuidad del de Cámpora disminuir las ataduras a la esfera de los Estados Unidos, diversificando el sistema de relaciones políticas y económicas externas, aumentando el peso de Europa, América Latina, el bloque socialista y los países afroasiáticos 
(Paradiso, 1993). Sin embargo, el carácter político tan marcadamente alineado a la izquierda de la “unidad continental” propuesta no sería el mismo. Roberto Russell afirma que “...la oposición a Estados Unidos durante el gobierno de Cámpora, ciertamente uno de los capítulos importantes del giro nacionalista y antiimperialista que adoptaron las políticas exteriores de varios países de la región a principios de los setenta, nunca tuvo consenso dentro del propio movimiento peronista. Tras la renuncia de Cámpora, Perón volvió a encaminar la relación con Estados Unidos conforme a las pautas que había delineado en los cuarenta” (Russell, 2001: 131).

\section{La visita de la CIDH y la campaña "Los argentinos somos derechos y humanos”}

El golpe del 24 de marzo de 1976 produjo un giro en la relación con Estados Unidos. No hubo intervención directa de la CIA, como en el de Pinochet en Chile (1973), pero sí un apoyo político, económico y militar a la dictadura. El anuncio del plan de Martínez de Hoz, el 2 de abril, llevó a la Administración Ford a otorgar ayuda financiera a la Junta Militar encabezada por Videla. En los meses siguientes, fluyó también la asistencia militar. El ministro de economía, según la Casa Blanca, era una garantía tanto para los intereses económicos estadounidenses en la región, como para el combate contra la subversión. Las fuerzas armadas, después del auge de luchas populares inaugurado por el Cordobazo y del traumático retorno del peronismo, daban seguridades a Henry Kissinger de mantener al país en el rumbo occidental, cristiano y anticomunista. La Junta Militar parecía ser un resguardo para la seguridad nacional de Estados Unidos. Esto era suficiente para la administración republicana, a pesar de las voces en el Capitolio y en el propio Departamento de Estado que tempranamente cuestionaron la represión sistemática de los derechos humanos en Argentina. El gobierno encabezado por Jorge Rafael Videla, por su parte, quería evitar esas críticas y era consciente de que, siendo un año de elecciones presidenciales en Estados Unidos, se tornaba difícil para la Casa Blanca apoyar públicamente y sin matices a una junta militar responsable de una cruenta represión interna. $\underline{42}$

Dos días después del golpe se reunieron Kissinger y William D. Rogers, Subsecretario de Estado, y debatieron sobre Argentina y la postura que debía tomar la Casa Blanca frente al golpe. Mientras Rogers anticipaba que se derramaría mucha sangre y aconsejaba no apresurarse, Kissinger planteó que los golpistas requerían del estímulo estadounidense y no quería dar la idea de que serían hostigados por Washington. ${ }^{43}$ Estas dos posiciones resumían el debate dentro del Departamento de Estado: "Desde el 24 de marzo de 1976 quedaron expresadas dos posturas en el Departamento de Estado respecto al gobierno argentino. A aquellos que apoyaron decididamente la política de la dictadura se opuso la de quienes planteaban que no debían repetirse los errores cometidos en los casos chileno y uruguayo, que le valieron, al Departamento de Estado, quejas del Congreso y la opinión pública” (Mazzei, 2013: 22).

En un documentado libro, Marcos Novaro cuestiona la idea del fuerte apoyo del gobierno de Estados Unidos al golpe, y plantea que, ya bien por la experiencia adquirida tras los golpes en Chile y Uruguay, ya bien porque pocos meses después habría elecciones presidenciales -donde el tema del apoyo a las dictaduras latinoamericanas fue parte del debate entre Ford y Carter-, prevaleció una postura más bien prescindente: 
“Argentina fue, ya entre 1975 y 1976, un caso aparte en el Cono Sur, tanto debido a la complejidad de los conflictos políticos que la atravesaban, como a la virulencia que había alcanzado en ella el fenómeno de la violencia política, y al menos así fue tratada por parte de una porción de la diplomacia norteamericana; lo que implicó que, más allá de las preferencias pro militares y anticomunistas que la guiaban (especialmente intensas en el caso de su jefe, el secretario de Estado Kissinger), esta mantuviera una actitud que en términos generales podemos denominar 'prescindente' frente al golpe de Estado (...)” (Novaro, 2011: 23).

A nuestro juicio, Novaro se circunscribe a las posiciones dentro del Departamento de Estado y soslaya, en cambio, el boicot financiero del FMI al gobierno de Isabel Perón en los meses previos al golpe, y el flujo de créditos que se dio a la Junta Militar en sus primeras semanas. Además, no toma en cuenta que, más allá de las posiciones diferentes en el Departamento de Estado -por ejemplo, las fuertes divergencias entre Kissinger y el propio embajador en Buenos Aires, Robert C. Hill-, en realidad terminó prevaleciendo la posición del jefe de la cancillería estadounidense. Escudé y Cisneros, a diferencia de Novaro, resaltan el fuerte apoyo estadounidense al golpe:

“... la emergencia de un gobierno autocrático en la Argentina fue percibida como una salida 'necesaria' al caos generado por el gobierno de Isabel Perón. Así, desde Washington, medios de prensa y organismos oficiales emitieron evidentes gestos de la posición favorable de la administración Ford hacia el nuevo gobierno argentino. Un cable proveniente de la capital norteamericana informó acerca de la 'buena disposición' con que el Fondo Monetario Internacional saludaba al régimen militar argentino, mencionándose la posibilidad de que el gobierno de Videla obtuviese un crédito santadby por 300 millones de dólares. A su vez, el propio gobierno de Ford recomendó el envío a los militares argentinos de 49 millones de dólares en concepto de asistencia militar para el año 1977. Por cierto, estos gestos demostraron la positiva repercusión que en las autoridades y los hombres de negocios norteamericanos tuvo el plan liberal del ministro Martínez de Hoz, que apuntaba a la apertura financiera y la atracción del capital extranjero. Desde la óptica de la administración Ford, la política económica de Martínez de Hoz era una 'garantía de los intereses de la política económica exterior de los EE.UU.' y el gobierno de Videla constituía 'un factor de perfecta estabilización' después de 'las luchas con características de casi guerra civil' en los años de las administraciones peronistas” (Cisneros y Escudé, 2000: 293).

Ya en junio, la CIA tenía conocimiento de la existencia del Plan Cóndor, la coordinación represiva con las dictaduras de Argentina, Chile, Bolivia, Perú y Paraguay para el asesinato secreto de perseguidos políticos. Sin embargo, ambas tendencias en el Departamento de Estado caracterizaban a Videla como la línea moderada dentro de la Junta Militar que gobernaba Argentina y eran renuentes a atacarlo directamente, supuestamente para no fortalecer su desplazamiento por parte de la línea dura.

Desde nuestra perspectiva, más que concluir que, a diferencia de los casos de Chile o Uruguay, en el caso argentino primó la política de hands off -de prescindencia o de distancia-, en realidad ocurrió algo similar que una década atrás. Como mostramos más arriba, en 1966, a pesar de las simpatías para con Onganía, el reconocimiento diplomático de su gobierno se demoró unos días, distinguiéndose de lo que había ocurrido dos años antes con el golpe contra Goulart en Brasil. Eso respondía a la necesidad de guardar las formas. Lo mismo puede decirse respecto al golpe de 1976. 
Más que una política de no intromisión, lo que hubo fue un doble discurso por parte de Kissinger, planteando el público la preocupación por la violación de los derechos humanos, y en privado avalando el terrorismo de estado, ya conocido por el Departamento de Estado semanas después del golpe. En dos entrevistas entre Kissinger y el canciller César Augusto Guzzetti, en junio y septiembre de 1976, el primero respaldó el terrorismo de Estado y hasta sugirió que hicieran lo que tuvieran que hacer lo más rápidamente posible (Novaro, 2001: 70-73). $\frac{44}{\text { Y }}$ esto perduró, más allá de las voces disidentes en el propio gobierno estadounidense y en la opinión pública de ese país:

"El agravamiento de la situación de los derechos humanos multiplicó los reclamos de los congresistas norteamericanos y de una segunda línea del Departamento de Estado que impulsaban sanciones económicas y militares hacia la Argentina. No obstante, se impuso la postura de Kissinger de no importunar a las dictaduras latinoamericanas, consideradas aliadas en la lucha de Occidente contra el Comunismo” (Mazzei, 2013: 22-23).

La situación comenzó a cambiar en enero del año siguiente, cuando los demócratas volvieron a la Casa Blanca. Durante la presidencia del demócrata James Carter (1977-81), uno de los ejes de su política exterior fue denunciar el no respeto de los derechos humanos en determinados países:

“Desde 1977 el gobierno de Carter desplegó la política de promoción de los derechos humanos, en el marco de una estrategia global para recomponer la hegemonía norteamericana en el mundo, elemento que caracterizó la política de Washington hacia la dictadura argentina. La condena a las flagrantes violaciones de los derechos humanos por parte del régimen de Videla se combinó, en 1978, con la suspensión de toda ayuda militar a Argentina. La dictadura respondía a EE.UU. con acusaciones de 'intervención en los asuntos internos' y reproches sobre la incomprensión de Occidente respecto de su cruzada 'antisubversiva'...” (Rapoport y Spiguel, 2005: 57).

Claro que había al menos para Washington una doble vara. Mientras se sancionaba la violación de los mismos en Argentina, no se hacía lo propio con la dictadura de Augusto Pinochet en Chile, ni había una condena al Plan Cóndor, impulsado por la propia CIA.

Como consecuencia de este rasgo de la política exterior de su Administración, la relación con los militares argentinos atravesó distintas fricciones. El sustento material de los roces bilaterales debe comprenderse a la luz del nuevo triángulo económico con Estados Unidos y la Unión Soviética. El primer país era el abastecedor principal de las importaciones argentinas y sostenía financieramente el espiral de endeudamiento requerido por la política de dólar barato y la tablita de Martínez de Hoz. La Unión Soviética y los países de Europa del Este, por su parte, fueron el destino privilegiado de los cereales y las carnes argentinas. Este sorprendente vínculo con Moscú y sus satélites, que se remontaba, como señalamos más arriba, a la etapa de Lanusse, no hizo sino profundizarse desde 1979, cuando tras la invasión soviética a Afganistán, Estados Unidos lanzó un embargo comercial contra su rival, que el gobierno argentino decidió no acompañar. La guerra fría registraba una nueva escalada, y el tándem Videla-Viola la aprovechaba para favorecer a la reprimarización de la economía alentada por los grandes productores agropecuarios. 
La negativa argentina a participar en el embargo contra la Unión Soviética, sumada a las acusaciones por violación de los derechos humanos y a la negativa a apoyar la política de Washington de no proliferación nuclear en América Latina tensaron las relaciones con la Casa Blanca. Carter ejerció presión sobre Videla de distintas formas: no vendiendo armamentos, limitando la provisión de bienes estratégicos e impulsando una misión de la OEA que llegó al país a recoger acusaciones sobre el terrorismo de Estado. Hubo una negociación entre el gobierno argentino y el Departamento de Estado para aceptar la llegada de esta misión a cambio de que no realizara un informe demasiado duro contra la Junta Militar encabezada por Videla (Novaro, 2011: 117-155). Sin embargo, el informe de la CIDH dejó muy mal parado al gobierno e incrementó las presiones externas e internas. De todas formas, la gran banca privada, liderada por David Rockefeller, siguió financiando a la Junta, y lo propio ocurrió con el Tesoro estadounidense. De esta forma, continuaron fluyendo los créditos hacia Argentina. Los contactos de Martínez de Hoz con el gran capital estadounidense, entonces, limitaron las sanciones esbozadas por Carter. Además, en 1979 triunfó en Nicaragua la Revolución Sandinista, con lo cual Washington incrementó la política dura de combate contra el comunismo en América. En consecuencia, se fortalecieron las críticas estadounidenses al énfasis de Carter en el tema de las violaciones de los derechos humanos por parte de las dictaduras aliadas. La guerra fría obligaba a hacer la vista gorda.

Veamos ahora, más en detalle, la visita de la CIDH, que se prolongó entre el 6 y el 20 de septiembre de 1979, y las movilizaciones que generó. Este intento de Videla de "lavarse la cara” ante Estados Unidos y el resto del mundo fue aprovechado por algunos dirigentes de partidos políticos, y también con los sectores de las fuerzas armadas que desaprobaban la táctica videlista de haber aceptado esta visita. $\underline{45}$

Diversas corporaciones se plegaron a la posición oficial de la junta militar y respaldaron su accionar en una solicitada, que pretendía contrarrestar las denuncias de los organismos de derechos humanos. La Sociedad Rural Argentina, el Rotary Club de Buenos Aires, el Centro de Exportadores de Cereales, Cámara Argentina de Frigoríficos, la Federación de Cámaras de Exportadores de la República Argentina, el Centro Argentino de Ingenieros, la Cámara Argentina de Productos Avícolas, la Unión General de Tamberos, el Consejo Empresario Argentino y el Consejo Publicitario Argentino, entre otras entidades, respaldaron así públicamente la "lucha antisubversiva” encarada a partir de marzo de 1976. $\underline{46}$ También la denominada “Agrupación Democrática Argentina” repudió el informe de la CIDH.

Estas expresiones acompañaron la campaña gubernamental que llamaba a la población civil a manifestarse bajo la consigna "Los argentinos somos derechos y humanos". $\underline{47}$ Pese a esta campaña, la visita, impulsada por organismos de derechos humanos, logró dejar asentadas miles de denuncias. Como recuerdan a algunos de los protagonistas:

“La comisión estuvo del 7 al 10 en Buenos Aires, del 10 al 14 en Córdoba, 14 y 15 en Tucumán, pasó por Rosario y regresó a la Capital Federal. Visitó los campos clandestinos de detención de La Rivera y La Perla, en Córdoba, y El Atlético, el Olimpo y la ESMA, en Buenos Aires que, como se comprobó más tarde, habían sido desmantelados por los militares para evadir la investigación. Estuvieron en las cárceles de Devoto, Caseros y Rawson. Se entrevistaron dos veces con la junta militar y con 
Videla, se reunieron con los organismos de derechos humanos: APDH, LADH, MEDH, Madres de Plaza de Mayo y Familiares; vieron a los ex presidentes Isabel Martínez, detenida en la quinta de San Vicente, Alejandro Lanusse, Arturo Frondizi y Héctor Cámpora, que se encontraba asilado en la embajada de México. También recibieron a la Conferencia Episcopal y a los políticos Ricardo Balbín y Raúl Alfonsín (UCR), Deolindo Bittel (PJ), Diego May Zubiría y Rafael Marino (PI), Enrique De Vedia y Francisco Cerro (DC) y Simón Lázara (PSU). A los sindicalistas de la CUTA, empresarios de la UIA, CAME, Sociedad Rural y ADEBA; a la AMIA y la FUA, a la Sociedad Central de Arquitectos y las asociaciones de psiquiatras y psicólogos, al Colegio de Abogados y en entrevistas personales a Lorenzo Miguel, Ernesto Sabato, Jacobo Timerman y Alfredo Bravo. Abrieron tres oficinas en todo el país y recibieron 5580 denuncias de secuestros y desapariciones 'la mayoría de ellas nuevas', o sea aparte de las casi tres mil que habían presentado los organismos. La comisión se fue del país el 20 de septiembre y en diciembre presentó a la dictadura un informe preliminar donde criticaban duramente el 'Estado de excepción’ que existía en Argentina y denunciaban la existencia de miles de desaparecidos. El informe final se conoció un año después en forma de libro. La dictadura prohibió su difusión y su venta. Pero había comenzado la cuenta regresiva y los represores comenzaban a preocuparse por el futuro". $\underline{48}$

En síntesis, más allá de la táctica del videlismo, la visita de la CIDH provocó una movilización hasta entonces inédita que escapó a su control y le abrió a la dictadura un complejo frente externo. No casualmente, Pérez Esquivel recibiría poco después el Premio Nobel de la Paz (octubre de 1980) y arreciarían las presiones internacionales por las violaciones de derechos humanos en Argentina. Internamente, marcó también el inicio de una creciente movilización popular contra la dictadura, que se manifestaría también en la activación sindical, a través del llamado a huelgas con movilización, como fue la masiva de marzo de 1982, poco antes del inicio del conflicto de Malvinas.

\section{Conclusiones}

En este artículo exploramos una problemática poco analizada en los estudios sobre relaciones internacionales y política exterior argentina: la incidencia de la movilización social. Nos enfocamos en analizar la movilización popular frente a cuatro visitas destacadas, una en cada uno de los períodos políticos analizados (los sucesivos gobiernos de Illia, la Revolución Argentina, el peronismo y la dictadura militar).

En los cuatro casos observamos cómo las visitas vehiculizaron conflictos políticos internos (la lucha por la vuelta de Perón, las críticas a la dictadura de Onganía, la izquierdización de una parte importante del peronismo o la incipiente lucha de los organismos de derechos humanos) y a la vez influyeron y condicionaron, en parte, la política exterior. En la mayoría de los casos, reflejaban las intenciones de los gobiernos y la reacción de los apoyos políticos y la oposición.

En el caso de Illia, la movilización que acompañó a la llegada de De Gaulle constituyó una medida del poder de presión del peronismo y una ratificación del sentimiento antiestadounidense que primaba en buena parte de los sectores populares. Sin duda constituyó un hito respecto del movimiento peronista opositor al gobierno y un argumento para quienes esperaban ansiosos la posibilidad de derrocarlo. La figura del presidente Francés operaba como símbolo de la disputa por 
esferas de influencia que Europa pretendía recuperar frente a los Estados Unidos y de las aspiraciones nacionalistas de sectores del peronismo. Para la CGT constituyó la posibilidad de una especie de puesta en escena mientras se elaboraba el luego fracasado Operativo Retorno de Perón.

En el caso del repudio a la visita de Rockefeller, constituyó una expresión del auge de la movilización popular iniciado un mes antes, con el Cordobazo, y la creciente presencia de un sindicalismo clasista y de una nueva CGT, la de los Argentinos, con la que confluyeron, por ejemplo, los grupos de intelectuales y artistas que organizaron la muestra "Malvenido $\mathrm{Mr}$ Rockefeller”. Como en otros países latinoamericanos, el representante de Estados Unidos debió enfrentar la creciente yanquifobia, profundizada por el accionar de su gobierno en Vietnam, pero también por la participación de la CIA en el asesinato del Che en Bolivia, en octubre de 1967. Los sectores de las clases dominantes que se reunieron con Rockefeller, y el propio gobierno argentino, si bien reprimieron fuertemente las protestas, pretendieron utilizarlas para presionar a Estados Unidos en pos de lograr concesiones. No es casual que, en su balance del largo periplo por 20 países de la región, Rockefeller planteara a su gobierno que era necesario realizar cambios importantes en la política hacia América Latina y el Caribe. La incapacidad de Onganía de evitar estas expresiones populares frente a la visita del representante de Estados Unidos es una muestra de su creciente debilidad, que lo obligaría, unos meses después, a abandonar la Casa Rosada.

La movilización popular que se produjo cuando asumió Cámpora, y en particular frente a la llegada de los mandatarios chileno y cubano, refleja las transformaciones internas del peronismo y el inicio de una nueva política hacia América Latina, que se materializaría en una orientación más autónoma de la política exterior. Era el emergente también del alivio y alegría social que había producido el fin de una larga dictadura, pero también una demostración de fuerza de un sector del peronismo, que intentaría terciar frente a las tendencias más tradicionales y conservadoras. Prefiguraría también el acercamiento hacia Cuba y los intentos del nuevo gobierno argentino de avanzar hacia una reforma de la OEA y el sistema interamericano en su conjunto. Este tipo de manifestaciones, entre otros motivos, obligaron luego a Nixon a plantear la necesidad de un Nuevo Diálogo con la región claro, también para morigerar la oposición que había generado el apoyo al golpe de Pinochet contra Allende, en septiembre de ese mismo año-. La participación y las aspiraciones de la juventud peronista, así como su alineamiento con proyectos de "liberación” latinoamericana, despertarían el rechazo de los sectores más conservadores y de los más reaccionarios dentro del propio peronismo. Así, la asunción de Cámpora fue el síntoma del interregno en el cual algunos países del continente aspiraron a transformaciones más profundas de sus sociedades, y al mismo tiempo, de la izquierdización del peronismo como proyecto antiimperialista.

Por último, la impresionante movilización de los organismos de derechos humanos y familiares de las víctimas del terrorismo de estado, a pesar de la campaña “nacionalista” de la Junta contra la injerencia de la $\mathrm{CIDH}$, mostró con contundencia la imposibilidad de erradicar la movilización social, incluso para las dictaduras más cruentas. Esta visita, y la reacción popular que logró con singular valentía romper el cerco de la censura y el miedo, ampliaron las presiones externas e internas contra una dictadura que en ese momento parecía inexpugnable. Esta movilización popular constituyó una dura derrota para la Junta Militar y sus aspiraciones de obtener apoyos civiles por parte de los partidos políticos. 
Entendemos que el análisis de estos cuatro casos muestran la importancia de tener en cuenta la movilización social para comprender mejor la política exterior argentina, lo que implica inscribirla en un amplio entramado político, económico y social. A la vez que en estos casos la expresión popular era respuesta a una visita extranjera, incidía en el rumbo de la política internacional, condicionándola, es decir, marcándole límites o al menos ejerciendo presiones. Sin desconocer las variables fundamentales que explican en cada caso la política adoptada, y en particular el predominio de la decisión del Poder Ejecutivo en el ámbito de la definición del rumbo de la política externa, consideramos que el análisis de esta variable interna puede aportar elementos generalmente descuidados en el estudio de las relaciones internacionales.

\section{Notas}

1 Este trabajo es parte de la investigación que desarrollamos en el marco del Proyecto PIP CONICET (2015-2017) "Los condicionantes domésticos de la inserción internacional argentina. Presiones, debates y movilizaciones en torno a la política exterior desde la década de 1960 a la actualidad” y del Proyecto UBACyT (2016-2017): "Política exterior, inserción económica internacional y movilización popular a lo largo de dos décadas turbulentas de la historia argentina (1963-1983)”, dirigidos por Míguez y Morgenfeld.

$\underline{2}$ Para un análisis pormenorizado de esta visita a la Argentina y de la visita al resto de los países latinoamericanos ver Míguez (2013b) y Míguez (2015).

$\underline{3}$ “Charles de Gaulle en Buenos Aires”, Revista Primera Plana No 100, 6 de octubre de 1964, p. 9. 4 Ibídem.

$\underline{5}$ “Argentina intenta obtener facilidades aduaneras en el mercado común europeo”, Diario ABC, Madrid, 6 de octubre de 1964, p. 64.

6 Compte Rendu. Entretien entre le Général de Gaulle et le Président Illia, Buenos Aires, le 4 octobre. Nota al pie (Documents Diplomatiques Français, 2002, 302). [Traducción propia]

Z Compte Rendu. Entretien entre le Général de Gaulle et le Président Illia, Buenos Aires, le 4 octobre. Nota al pie (Documents Diplomatiques Français, 2002, 302). [Traducción propia]

$\underline{8}$ “Argentina intenta obtener facilidades aduaneras en el Mercado Común Europeo”, Diario ABC de Madrid, 6 de octubre de 1964, p. 64.

q Télégramme immédiat de Jaquin de Margerie, Ambassadeur de France à Buenos Aires, à M. Couve de Murville, Ministre des Affaires Étrangères, Buenos Aires, le 6 octobre 1964, 23 hs. 10, Documents Diplomatiques Français, 1964, Tomo II, Ministère des Affaires étrangères, P.I.E, Peter Lang, Bélgica, 2002, p. 305 y 306. [Traducción propia]

10 “Una herida que fue más allá del dedo”, en Revista Primera Plana No 101, 13 de octubre de 1964, p. 8.

11 “Charles de Gaulle en Buenos Aires”, Revista Primera Plana No 100, 6 de octubre de 1964, p. 9. 
12 Télégramme immédiat de Jaquin de Margerie, Ambassadeur de France à Buenos Aires, à $\mathrm{M}$. Couve de Murville, Ministre des Affaires Étrangères, Buenos Aires, le 6 octobre 1964, 23 hs. 10, Documents Diplomatiques Français, 1964, Tomo II, Ministère des Affaires étrangères, P.I.E, Peter Lang, Bélgica, 2002, p. 305 y 306. [Traducción propia]

13 Para un pormenorizado análisis de la visita de Rockefeller en el contexto de las relaciones entre Argentina y Estados Unidos, véase Morgenfeld (2013).

14 Más allá de esta concesión, se mantuvieron los “créditos atados”, que era lo otro que los países del sur, en el Consenso de Viña del Mar, habían solicitado que se suprimiera.

$\underline{15}$ “Una convulsa Argentina recibe hoy a Rocky”, Excelsior, 29 de junio de 1969.

16 La Razón, 30 de junio de 1969.

$\underline{17} 62$ artistas plásticos, entre los cuales se encontraba Ricardo Carpani, se reunieron en Buenos Aires para montar una muestra de repudio, que fue clausurada violentamente al día siguiente de su inauguración, siendo destruidas luego varias de sus obras.

18 Revista Siete Días Ilustrados, 30 de junio de 1969.

19 Saccio a Rockefeller, Buenos Aires, 06/05/1969; en Rockefeller Archive Center (RAC), R. Family, RG 4 NAR, Series O, Box 173, Folder 1413. Saccio adjunta un completo informe de 16 páginas, producido por la Embajada de Estados Unidos en Buenos Aires, en el que se destacan distintos aspectos de la relación bilateral, incluyendo el comercio de carnes, la asistencia militar, los acuerdos de no proliferación nuclear o la posición estadounidense en el conflicto argentinobritánico por Malvinas.

$\underline{20}$ En RAC, R. Family, RG 4 NAR, Series O Subseries 8, Box 180, Folder 1480.

21 "Excerpts of Remarks by Governor Nelson A. Rockefeller prepared for delivery of arrival, in Argentina, June 29, 1969”, RAC, R. Family, RG 4 NAR, Series O, Box 173, Folder 1413.

$\underline{22}$ "Press briefing by Governor Nelson A. Rockefeller of American Press, Hotel Plaza, Bs As, June 30, 1969, 4PM”, RAC, R. Family, RG 4 NAR, Series O, Box 173, Folder 1413.

$\underline{23}$ “Breakfast Meeting with Private Sector in Buenos Aires, June 30, 1969”, RAC, R. Family, RG 4 NAR, Series O Subseries 8, Box 149, Folder 1207.

24 En RAC, R. Family, RG 4 NAR, Series O Subseries 8, Box 149, Folder 1206. [Subrayado en el original]

$\underline{25}$ Hemos analizado en forma pormenorizada los vaivenes de la política exterior durante los gobiernos de Cámpora y Perón en Míguez (2016).

$\underline{26}$ “Ochenta y seis naciones se hicieron representar en la ceremonia de la transmisión de mando”, Diario Clarín, 26 de mayo de 1973, p. 12.

$\underline{27}$ “Destaca la prensa uruguaya inconvenientes de Bordaberry en los actos del 25 de mayo”, Diario Clarín, 28 de mayo de 1973, p. 6 
$\underline{28}$ “Muestras de apoyo a Chile, Cuba y Perú”, Diario La Nación, 25 de mayo de 1973, p. 19. $\underline{29}$ Diario La Nación, 26 de mayo de 1973, p. 6.

$\underline{30}$ “Homenaje de la Asamblea Legislativa a las misiones”, Diario La Nación, 27 de mayo de 1973, p. 10.

$\underline{31}$ Para las relaciones bilaterales entre la Argentina y la Unión Soviética en el período ver: Rapoport (1995), Vacs (1984) y Laufer y Spiguel (1998).

$\underline{32}$ “Las relaciones con Cuba se reanudan”, Diario La Nación, 29 de mayo de 1973, p. 1.

33 “Argentina otorgó a Cuba un crédito de 200 millones de dólares y está en vías de integrarse al Grupo Andino”, Diario La Opinión, 7 de agosto de 1973, p. 1.

34 “Argentina otorgó a Cuba un crédito de 200 millones de dólares y está en vías de integrarse al Grupo Andino”, Diario La Opinión, 7 de agosto de 1973, p. 1.

$\underline{35}$ “Fueron recordados los hechos ocurrido en Córdoba en 1969”, Diario La Prensa, 30 de mayo de 1973, p. 12.

$\underline{36}$ “Visita a Córdoba del presidente Dorticós”, Diario La Nación, 30 de mayo de 1973, p. 8.

37 Ibídem.

$\underline{38}$ “Visita a Córdoba del presidente Dorticós”, Diario La Nación, 30 de mayo de 1973, p. 8.

$\underline{39}$ “Cálida acogida a Dorticós”, Diario Clarín, 30 de mayo de 1973, p. 10.

40 “Formas de unidad americana”, Diario La Prensa, 29 de mayo de 1973, p. 7.

41 Citado en “Comienza un desafío al colonialismo y al imperialismo en América Latina”, Diario La Opinión, 26 de mayo de 1973, p. 2.

42 Para un análisis de la posición de Estados Unidos frente a la dictadura, ver Morgenfeld (2014).

43 Secretary’s Staff Meeting, 26 de marzo de 1976, pp. 19 a 23 (Cit. Mazzei, 2013). La transcripción y traducción de ese diálogo está reproducida en Novaro (2011: 59-50)

44 Novaro reproduce parte de la transcripción del segundo encuentro entre Kissinter y Guzzetti, del cual el último volvió “eufórico” (Novaro, 2011: 70-73). Véanse también Sheinin (2006: 163-164) y Rabe (2012: 143).

45 La delegación de la CIDH la integraban su presidente, el venezolano Andrés Aguilar, el costarricense Luis Timoco Castro, el norteamericano Thomas Farer, el colombiano Marco Monroy Cabral, el brasileoo Carlos Alberto Dunshoe de Abranches, el salvadoreño Francisco Bertrand Galindo y el chileno Edmundo Vargas Camaño. En Buenos Aires, se entrevistaron con la Junta Militar, y también, entre otros, con María Estela Martínez de Perón, Lorenzo Miguel y Jacobo Timerman. Ver “Comisión de Derechos Humanos ¿Qué buscan?”, Somos, N 155, 7 de setiembre de 1979, pp. 4-9, (Cit. Cisneros y Escudé, 2000: 295).

46 Solicitada publicada en Convicción, 21 de septiembre de 1979, p. 5, (Cit. Cisneros y Escudé, 2000: 296) 
47 El mismo día que arribaba la $\mathrm{CIDH}$, el seleccionado juvenil de fútbol se consagraba campeón mundial. El relator oficial, Muñoz, arengaba por Radio Rivadavia: "Vayamos todos a la Avenida de Mayo y demostremos a los señores de la Comisión Interamericana de Derechos Humanos que la Argentina no tiene nada que ocultar.”

48 “Cuando el telón comenzó a levantarse”, Diario Página/12, 29 de agosto de 1999.

\section{Referencias Bibliográficas}

Alonso, Enrique (1973). “El discurso de Cámpora”, Diario La Opinión, 26 de mayo de 1973, p. 7

Baschetti, Roberto (1997). Documentos de la resistencia peronista 1955-1970, La Plata: Editorial De La Campana.

Bonasso, Miguel (2006). El presidente que no fue, Buenos Aires: Planeta.

Castello, Antonio Emilio (1986). La democracia inestable, Tomo II (1962-1966), Buenos Aires: Ediciones La Bastilla.

Colby, Gerald y Dennett, Charlotte (1995). Thy Will be Done, the Conquest of the Amazon: Nelson Rockefeller and Evangelism in the Age of Oil, New York: Harper Collins Publishers.

De Gaulle, Charles (1971). Memoires d'espoir, Le Renouveau (1958-1962), Paris: Librairie Plom.

Documents Diplomatiques Français, 1964, (2002) Tomo II, Ministère des Affaires étrangères, P.I.E, Bélgica: Peter Lang.

García Lupo, Rogelio (1964). ¿A qué viene Perón?, Jorge Álvarez Editor: Buenos Aires.

Horowicz, Alejandro (1973). “Concluye el aislamiento comercial de Cuba respecto de América Latina”, Diario La Opinión, 8 de agosto de 1973, p. 11.

Laufer, Rubén y Spiguel, Claudio (1998). "Europa Occidental en las relaciones internacionales argentinas del mundo bipolar, 1970-1990”, en Revista Ciclos en la historia, la economía y la sociedad, $\mathrm{N}^{\mathrm{o}} 14-15$, 1er. semestre.

Mazzei, Daniel (2013). “El águila y el cóndor. La relación entre el Departamento de Estado y la dictadura argentina durante la Administración Ford (1976-1977)”, Revista Huellas de Estados Unidos, Núm. 5, septiembre.

Míguez, María Cecilia (2013). “La visita de De Gaulle a la Argentina en 1964 y las repercusiones en las fuerzas políticas internas”, Revista Relaciones Internacionales № 45, Instituto de Relaciones Internacionales, Universidad Nacional de La Plata.

Míguez, María Cecilia (2015). "De Gaulle en América Latina. Estados Unidos, Europa y un continente convulsionado", en Revista E-L@tina, Revista Electrónica de Estudios Latinoamericanos, Vol 13, N 52, FSOC, Universidad de Buenos Aires. 
Míguez, María Cecilia (2016). “Conflicto político interno, política exterior y el rol de América Latina: tensiones abiertas en el tercer gobierno peronista”, Revista Estudios № 36 [en prensa], Universidad Nacional de Córdoba.

Morgenfeld, Leandro (2013). “Nelson A. Rockefeller en la Argentina: una visita incómoda tras el Cordobazo", Revista Taller, Segunda Época, Volumen 2, Número 2, julio 2013, pp. 90-104.

Morgenfeld, Leandro (2014). “Argentina y Estados Unidos, golpe a golpe (1966-1976)”, en SAAP. Publicación de Ciencia Política de la Sociedad Argentina de Análisis Político, Vol. 8, N. 2, noviembre 2014, pp. 521-554.

Novaro, Marcos (2011). Cables secretos. Operaciones políticas en la Argentina de los setenta, Buenos Aires: Edhasa.

Page, Joseph (1984). Perón. Segunda parte (1952-1974), Buenos Aires: Ed. Javier Vergara.

Nelson A. Rockefeller (1969). The Rockefeller report on the Americas: The official report of a United States Presidential mission for the Western Hemisphere, Chicago: Quadrangle Books.

Paradiso, José (1993). Debates y trayectorias de la política exterior argentina, Buenos Aires: Grupo Editor Latinoamericano.

Portantiero, Juan Carlos (1973). “Trascendencia de una decisión política que replantea la línea internacional”, Diario La Opinión, 29 de mayo de 1973, p. 8.

Rabe, Stephen (2012). The Killing Zone. The United States Wages Cold War in Latin America, New York: Oxford University Press.

Ramírez, Francisco (1973). “Decisivo apoyo a la tecnificación del agro puesta en marcha por Fidel Castro”, Diario La Opinión, 9 de agosto de 1973, p. 12.

Rapoport, Mario (1995). “La Argentina y la Guerra Fría. Opciones económicas y estratégicas de apertura hacia el Este (1955-1973) en Revista Ciclos en la Historia, la economía y la sociedad, Año V, vol. 8, Buenos Aires, 1er. Semestre.

Rapoport, Mario y Spiguel, Claudio (2005). Política Exterior Argentina. Poder y conflictos internos (1880-2001), Buenos Aires: Capital Intelectual.

Russell, Roberto (2001). “La política internacional (1945-1983)”, en Academia Nacional de la Historia. Nueva Historia de la Nación Argentina. Tomo VIII, Buenos Aires: Planeta.

Sheinin, David (2006). Argentina and the United States. An alliance contained, Athens: University of Georgia.

Svampa, Maristella (2003). “El populismo imposible y sus actores (1973-1976)” en James, Daniel 2003 Violencia, proscripción y autoritarismo (1955-1976) Nueva Historia Argentina, Buenos Aires: Sudamericana.

Vacs, Aldo J. (1984). Los socios discretos, Buenos Aires: Sudamericana. 